\title{
\#MeToo and the Promise and Pitfalls of Challenging Rape Culture through Digital Feminist Activism
}

\author{
Kaitlynn Mendes, University of Leicester \\ Jessica Ringrose, University of London, Institute of Education \\ Jessalynn Keller, University of Calgary
}

On 24 ${ }^{\text {th }}$ October 2017, the \#MeToo hashtag began trending on Twitter. Although the phrase was initiated by African American women's rights activists Tarana Burke in 2006, it gained widespread attention when actress Alyssa Milano used it as a Twitter hashtag in response to allegations of sexual assault by Hollywood producer Harvey Weinstein. Through the \#MeToo hashtag, Milano encouraged members of the public to join in to showcase the magnitude of the problem of sexual violence. Capturing both public and media attention, the hashtag was used 12 million times in the first 24 hours alone (CBS, 2017).

Since 2014, we have been studying the ways feminists have increasingly turned to digital technologies and social media platforms to dialogue, network and organise against contemporary sexism, misogyny and rape culture (see Mendes et al., forthcoming). 'As a research team the sheer volume of attention paid towards this hashtag took us by surprise, but the fact survivors took to social media to share their experiences and engage in a 'call-out culture' resonated strongly with our research findings over the past three years. Although \#MeToo is perhaps one of the most high-profile examples of digital feminist activism we have yet encountered, it follows a growing trend of the public's willingness to engage with resistance and challenges to sexism, patriarchy and other forms of oppression via feminist uptake of digital communication. 
We are not alone in studying the range of tactics women (and some men) are using to make visible and challenge rape culture, misogyny and harassment (see Baer, 2016; Olson, 2016). In recent years, feminist media studies scholarship has documented the ways digital spaces are often highly creative sites where the public can simultaneously learn about and intervene in rape culture (Horeck, 2014; Rentschler, 2015; Keller et al., 2016; Thrift, 2014; Phipps et al., 2017). What makes our study and findings unique is not only our attention to how these digital tools are being used, but our mapping of the experiences of those involved. In addition to analysing over 800 pieces of digital content, including blog posts, tweets, and selfies, we collected the views of 82 girls, women and some men around the world, including organisers of various feminist campaigns, and those who have contributed to them. What follows below is an overview of some key findings from our forthcoming book (Mendes et al., forthcoming) which highlight the promise, potential and pitfalls of doing digital feminist activism. Indeed, as we have found from our study, digital feminist activism is far more complex and nuanced than one might initially expect, and a variety of digital platforms are used in a multitude of ways, for many purposes. Furthermore, although it may be technologically easy for many groups to engage in digital feminist activism, there remain emotional, mental or practical barriers which create different experiences, and legitimate some feminist voices, perspectives and experiences over others.

\section{Hashtag Feminism and Social Change}

Hashtag feminism is one of the most popular forms of feminist activism and involves using hashtags (the \# symbol followed by a thematic word of phrase) to produce communities of conversation among disparate Twitter users (Berridge and PortwoodStacer, 2015; Dixon, 2014; Horeck, 2014). While hashtag feminism has received 
substantial attention from mainstream media, we still know very little about what hashtags like \#MeToo actually do; or whether and how they can produce social change. We also have scarce research that takes stock of what engaging with hashtags actually looks and feels like. One of our research case studies, the \#BeenRapedNeverReported hashtag which trended in 2014 (see Keller et al., 2016 for detailed discussion of this hashtag), functioned very similarly to \#MeToo in the ways in which it was used by girls and women to share personal stories of sexual violence and why they didn't report them to authorities. The case study provides some significant insights into the promise of digital feminist activism for raising feminist consciousness and producing solidarity.

As part of this case study we analysed hundreds of \#BeenRapedNeverReported tweets and interviewed several girls and women who used this hashtag to share their experiences of sexual violence. While we understood that the hashtag touched a cultural nerve that propelled it to be circulated millions of times (Teotonio, 2014), our interviews revealed the complex terrain of emotions that sustained the 'tsunami' (Teotonio, 2014) of \#BeenRapedNeverReported tweets. We discovered that these tweets were not flippant responses, but carefully produced testimonials that were scaffolded after sleepless nights. One participant told us:

It was very emotional and it was very upsetting to me, this whole thing, being a part of that hashtag, reading other women's little tweets, 140-character tweets. One resonated and it was really a tough couple of weeks. Even though it was positive, it was very, very difficult for me. There were some nights where I didn't sleep.

This comment reflects the ways in which participating in a hashtag like \#BeenRapedNeverReported is often both triggering and comforting to participants, a 
tension that was common amongst almost all our interviewees, and must be recognized as part of the complexity of doing digital feminist activism.

Yet despite the difficult emotions raised by the hashtag, our participants spoke of the significant support they received from tweeting about their assaults. One woman reported:

I got an overwhelming awesome response the night I posted ... There was one... all she said was, 'we stand with you, friend.' And that one made me cry. I'll admit it, that one made me cry. And then there was one that told me I was incredibly strong and brave for doing what I did.... there was six or seven comments like that. Which, for me, was overwhelming because I didn't really think that anyone would say these things, you know, it was just I was helping the hashtag understand why things weren't being reported. And I didn't really expect any response at all. And next thing you know, I got likes and favourites and comments, and I was just, like, oh, my gosh, what is going on here.

This comment is indicative of the support that many women received after using the \#BeenRapedNeverReported hashtag. Not only did the women we interviewed describe being surprised by public responses to their tweet, but many emphasized how much that support in the form of 'favorites,' 'retweets,' or 'DMs' (direct messages) from strangers meant to them as a form of solidarity and support. We cannot dismiss the significance of this, because if hashtags like \#BeenRapedNeverReported and \#MeToo are making survivors feel heard as our participant describes above, then they are doing meaningful and worthwhile work in building networks of solidarity.

We also discovered that this solidarity often transforms into a feminist consciousness amongst hashtag participants, which allows them to understand sexual violence as a structural rather than personal problem. For example, another one of our interviewees told us that she began to identify as a feminist only after sharing her story of sexual assault on social media. This experience allowed her to 
begin to understand her own history of sexual violence as part of a broader structural social problem, rather than an individual experience that arose from encounters with 'bad men.' Another young woman we interviewed, who was assaulted on a university campus told us that sharing her experience online was the first step in reporting her assault to the campus police:

For me, [sharing my story with the \#BeenRapedNeverReported hashtag] was kind of the strength to say I can report this. And so it gave me the option and the power to actually go through to campus security... I'm not sure if it was because I finally put my name to it [the assault] or because I had seen so many other stories. There was a solidarity with it where I felt comfortable and ready to.

By reporting her assault to campus police, this young woman is not only overcoming stigma on a personal level, she is also contributing to social change by challenging the stigma of reporting and making campus sexual assault more visible and knowable.

This brief overview of some of our interview findings suggest that hashtags like \#BeenRapedNeverReported and \#MeToo provide important opportunities for the development of feminist solidarity and consciousness, and even, social change. This is especially true for girls and women who may not be familiar with feminism as a personal and political imperative. Indeed, these shifts in consciousness may go undetected at first, but over time, this 'mainstreaming' of feminist activism is laying the foundation for a collective shift towards more just society.

\section{The Labour of Digital Feminist Activism}

It is perhaps easy to assume that the labour involved in running a feminist campaign such as \#MeToo, or \#BeenRapedNeverReported is minimal - after all, one only has to coin a hashtag and let the public take over. While to some extent, hashtag feminism 
is perhaps the 'easiest' type of digital feminist campaign to run, this does not mean that it is easy, or that there is no further labour after the initial conceptualisation or tweet. Indeed, when hashtags or other digital feminist campaigns gain momentum and are widely used, its founders often become subject to much mainstream attention, scrutiny and follow-on initiatives. The founders of \#BeenRapedNeverReported were regularly asked to write about the hashtag and its significance, and take part in media interviews and debates. Our interviews with eighteen feminist organisers showcase the often hidden labour involved in maintaining these campaigns, and public interest. In many cases, organisers devoted several hours each day or week to these initiatives with little to no financial compensation or regularly scheduled breaks. Like labour in offline settings, digital labour has been said to exploit the unpaid labour of those who use digital platforms and social media as sites of creativity, leisure, and increasingly, activism (see Duffy, 2015). Although more often than not, such work is undertaken because of individual's desire and passion for the subject (see also McRobbie, 2016), the fact remains that it is very difficult (and contentious) to seek financial compensation from this type of work. Like other types of 'women's work,' the labour involved in running these digital feminist campaigns is highly affective, precarious and exploitative - and as such, we raise questions about the sustainability of such unpaid labour in light of online abuse, burn-out, and other issues around work-life balance in the digital age.

Throughout our interviews, many participants talked about the emotional 'tax' they experienced from listening to stories of abuse, harassment, misogyny and sexism. This included the 'weightiness' of the work and how at times they had to take breaks, limit what they take on, and in some cases, walk away, even if only for a short time. As one organiser for the Tumblr site Who Needs Feminism? shared, 'It 
does get tiring and it does get...it's definitely emotionally taxing and you have to take care of yourself. I did have to take a break from it sometimes' (Tsai, 2015). Some of our participants talked about the panic attacks they felt as a result of the weight and sheer amount of work needed to run these campaigns. In sharing her experience of quitting Everyday Sexism shortly after taking up her first full-time academic position, Emer O'Toole explained how her exit was abrupt and unexpected:

I was sitting down to do the volunteer co-ordination and I was kind of going like, oh, having trouble breathing. And I just wrote to Laura [Bates of the Everyday Sexism Project] and said, "I'm so sorry, I can't do it, I can't even really train someone else up to take over from me. I'm so sorry but here's where everything's at, I just have to bow out right now." (O'Toole, 2015)

\section{Everyday Experiences of Doing Digital Feminist Activism}

So far, we have explored the experiences of using a hashtag for the first time to discuss experiences of sexual violence, as well as the experiences of feminist activists who are leading feminist campaigns and the emotional toll of the labour of communicative capitalism (Dean, 2005) that is a consequence of putting oneself out there 'in the line of fire' through online feminist activism. Our data also included an in-depth online survey targeted at everyday Twitter users who self-defined as 'feminist activists.' Our goal in collecting such a sample was to understand the everyday dynamics of living a feminist life and the role that digital culture played in making feminist politics possible. Moreover, we wanted to extend our analysis to contextualise the experiences of getting involved through social media to ask what happens after women and girls begin to participate in digital feminist politics around rape culture and sexual violence by posting on a trending hashtag? How do they sustain and build upon their feminist consciousness through their digital networks online? 
Survey participants were recruited through our own Twitter networks, generating forty-six responses (including four self-defined feminist men). Albeit a small sample, the responses were richly descriptive regarding participants' experiences of using Twitter for feminist activism, and specifically to combat rape culture. Indeed, all but two of our survey respondents (96 percent) reported that they had directly challenged sexual violence and 'rape culture' in their social media posts. We have three major findings from the survey data we want to highlight in the final sections of this paper: The positive potential of Twitter; hostility and trolling on Twitter; and finally, how engaging in feminist debate on Twitter is still understood as easier than discussing feminist views in real life, which further illustrates how important digital platforms are in providing spaces to develop both individual and collective feminist consciousness, and to find and maintain support for feminist views.

\section{Is Twitter a safe space for feminist activism?}

A first significant finding was that respondents identified overwhelmingly positive aspects of using Twitter to communicate their feminist views with much wider audiences than their immediate social circles.

The first place I heard about feminism was on the internet. Feminism saved my life. The internet has the ability to reach so many people, and if it can change my life, it can change theirs. I definitely see internet feminism as a form of activism with the potential to change society.

The themes of global reach, speed, immediacy, dialogue; visibility, engagement, contact, connection, collectivity and shared understanding all emerged as important for participants. For example, one respondent said Twitter was critical for sustaining her feminist politics because of: 
[T]he potential to connect with others. I have so many like-minded friends on Twitter now that I sometimes forget not everyone is as sensitive and understanding of issues around feminism, gender and trauma as they are. You can get involved in reacting a huge audience without putting yourself too much as risk too, i.e. retweeting or sharing information

Another added:

[Twitter] creates a safe space to explore new ideas. Meeting like- minded people, being educated by others tweets and blog posts and making new friends.

The idea of safe spaces to feel comfortable sharing, and connecting with 'likeminded' people and 'knowing that others feel the same as you' on Twitter was described as particularly important for learning, awareness and consciousness raising:

Twitter allows a greater number of people to engage in debate, it creates greater awareness, it provides a platform to address many issues relating to feminism and allows us to call people out when they make misogynistic comments. Through exposing them on a public forum, we might encourage one to re-evaluate their views and actions and hopefully encourage change

We can see that self-defined digital feminist activists feel very strongly that digital 'calling out' practices are a critical part of instigating social change. In addition, the issues of raising the visibility of feminism and enabling the voice of marginalised groups was voiced repeatedly:

Visibility is important and Twitter allows feminists to express opinions and share stories that aren't publicised in the mainstream. I'm a believer that the personal is political and if a person can connect to another's story their 
political views can be changed. Internet activism is also useful for activists with mental or physical disabilities who may not be able to attend protests and meetings.

Historically women have had little to no way to meet up and to discuss and share ideas, which has arguably lead to a narrow and white feminism being dominant, yet now through social media being accessible for many it is so much more easier to share ideas, to discuss and develop feminism, to help others through advice and through petitions, through raising awareness, and through holding others to a higher standard and pointing out others inexcusable misogyny.

Women's historical exclusion from the public sphere and participation in political debates are explained through reference to accessibility, ability, race and class privilege through what we might term an intersectional lens, typically understood to be a key aspect of 'fourth wave' digital feminism (Munro, 2013). Age was also raised several times as a critical aspect of being denied a political voice in many social contexts and structures, with Twitter offering an alternative space for political participation. Thirty-three per cent of the survey respondents were teenagers attending school, who argued Twitter provided knowledge and opportunities for learning and dialogue that school could not. Respondents also felt that they may be able to use social media information and learning to influence their known peers at school (see also Retallack et al., 2016; Kim and Ringrose, forthcoming):

[Twitter] is a platform that isn't available in school or in other aspects of my life. It allows me to show knowledge to those unaware as well as learn more myself.

I think the biggest benefit of using social media for my feminism is the fact that it helps me feel as if I'm making a difference, and interacting with a community, on a daily basis. In my high school environment, it's easy to forget that there are other people out there with the same progressive beliefs as me; the ability to interact with other feminists reminds me that there's still hope. 
I mostly tweet and retweet about what I find to be misogynistic. What I really think makes the most impact from my account, is that there are people from school I know following me that don't share my beliefs. The fact that they're seeing my opinions, is hopefully making them realize that these things are issues, and we have a responsibility to care about them.

\section{Does fear, hostility and trolling dominate Twitter?}

In recent years, in tandem with the growth in scholarship around the 'popularity' of feminism (see Banet-Weiser and Miltner, 2016; Gill, 2016; Keller and Ringrose, 2015), scholars are paying attention to how the rise of digital technologies has enabled the flourishing of much misogynist vitriol against feminism and even specific feminists (see Citron, 2014; Jane, 2014, 2017; Poland, 2016; Powell and Henry, 2017). Within our own study, trolling and online abuse was indeed a common experience, with 72 percent of our survey respondents experiencing negativity, hostility or trolling in response to their feminist views and challenges to rape culture online. Participants shared their experiences of a wide range of practices - from seemingly mundane, ubiquitous, or 'low-level' comments such as 'you're fat' or 'ugly' to vitriolic, violent and graphic rape and death threats:

I've had men be aggressively hostile, abusive and trolling - all unprovoked. I rarely enter into a dialogue, yet have had to block men who deliberately searched keywords and were randomly abusive.

I get called a bitch and an ugly whore pretty much weekly. I was also told that I deserved to be raped and that that would be the only way l'd ever get laid and that I should be grateful

Some of these episodes of what participants called 'trolling,' were recounted as involving persistent and multiple attacks from strangers on their Twitter feeds: 
It tends to be very predictable - anti-feminists popping up in response to a $\mathrm{RT} /$ comment/discussion and quite aggressively belittling the feminist point of view. Very rarely, if ever, do they respectfully challenge - rather they attempt to bully/dominate by demanding evidence/proof etc, and telling us in no uncertain terms that we are wrong. At best it's sarcastic and patronizing, at worst it's offensive - for example making reference to those who object to pornography as ugly/jealous/needing to be $f^{\star \star} k e d$.

Importantly, participants had developed a range of strategies to cope with these 'predictable' forms of anti-feminism, but also 'extreme' forms discussed such as 'meninism' and Men's Rights Activism (Ging, 2017); as well as sexually violent and shaming forms of 'mediated misogyny' (Vickery and Everbach, 2018). These strategies included purposefully avoiding engaging with aggressive tweets and blocking and muting these accounts. Some engaged in 'digilante' (digital vigilante see Jane, 2017) tactics, for example finding out the school attended by teen boys sexually harassing someone on Twitter and threatening to contact the boys' headmaster to report their activity. In another case one of our participants worked with Twitter headquarters and the police to locate and charge a serial troll who was creating multiple accounts to continue abusive activities. We found that despite threats women and girls encountered, designed to challenge their rights to political participation in the online pubic sphere (Salter, 2016) our participants largely persisted in their digital feminist activities.

\section{Is Doing Feminism Easier in Digital Spaces?}

The third and final finding we want to discuss in this short overview of our survey findings is how, despite the risk and hostility on Twitter, the digital sphere was still largely understood as a relatively safer and easier space to engage in feminist discussions than in participant's offline contexts. Moreover, we found that experiences of engaging with and developing feminist consciousness online actually 
created a range of clashes in their everyday relationships with colleagues, family and friends. The tension between their online feminist community where they could share views and opinions and get support contrasted strongly with experiences of dismissal by significant others in their everyday lives:

Most of my offline friends wouldn't identify as [feminist]. I have been really surprised and disheartened, when talking to them about feminism, by their reluctance to acknowledge the socially constructed nature of femininity and the influence of culture on behaviours/practices that they consider entirely free choices. I have found this frustrating, and at times upsetting because I have come away from some conversations feeling as though the problem lies with me - as though I'm imagining things, that it's about my personal issues, that I'm over-sensitive and so on. This has encouraged me to get more involved with feminism online, where I have found support and realised that I'm not alone (emphasis added)

Again, the issue of 'feeling alone' in one's feminist views and feeling upset by institutionalised cultures of sexism amongst friends and family as well as at work, school and university was salient. We are reminded of Sara Ahmed's (2010) figure of the feminist 'killjoy' and how discursively and affectively the person practicing feminism is positioned as the 'problem' and creating trouble and tension for others. Several teens experienced such tension with peers at school when they expressed their feminist views or challenged sexual violence through their uses of social media (see also Ringrose and Renold, 2016a). As one explained, 'Most of the negativity I've experienced online has been from people that actually know me from school.' Another confirmed 'The worst problems are in school. One person related my feminist tweet to fascism. Others made sarcastic remarks.... Some would make "jokes" that they know are sexist/racist.' These teens were not alone, and many others shared similar experiences, which demonstrate difficulties of being identified 
as a feminist as a young person within institutionalised cultures of sexism in and around schools (Ringrose and Renold, 2016b).

\section{Concluding thoughts}

In summary, when thinking about what hashtags such as \#MeToo actually do, and what platforms like Twitter can enable for feminist politics, the answer is complicated. Our findings of the lived experiences of posting on anti-rape hashtags, leading and participating in feminist campaign against sexual violence and developing feminist networks via Twitter reveal a complicated picture defined by contradictions. It is now common knowledge that digital technologies make the distribution of online vitriol easy, persistent and vicious; and a range of feminist research has suggested that Twitter is overwhelmingly a negative and toxic space for women (Jane, 2017; Shaw, 2014). In line with this, most participants experienced anxiety and fear of being attacked for their feminist views. However, in contrast, our findings also reveal how digital feminism can simultaneously be experienced as extremely positive in generating community, connection, and support for feminist views, and solidarity in calling out rape culture. Despite widespread fear of attack and experiences of trolling the participants found strategies to tackle this. Moreover, Twitter and online platforms were viewed by many participants as safer and easier spaces for engaging in feminist activism than offline places such as the street, workplaces, schools and amongst family and friends. This was particularly true for teenagers who found that practicing feminism offline at school was extremely difficult to navigate.

In conclusion, then, our findings lead us to be both optimistic and cautious about the experiences of viral digital movements such as \#MeToo, and many more like it (such as \#BeenRapedNeverReported and \#YesAllWomen). These campaigns are 
providing important spaces for a wider range of women and girls (in relation to age ability, race and other factors) to participate in public debates on sexual harassment, sexism and rape culture. These platforms are also making women's and girls' voices and participation visible in ways that can generate the type of ripple effect we have witnessed in the aftermath of \#MeToo, where many powerful, (mainly white) men are being held accountable for historic instances of abuse and harassment. At the same time, our findings clearly demonstrate that it is never easy to engage in such activism. Aside from the celebrated statements of defiance valorised by the media with cases such as \#MeToo, more hidden are the emotional, mental or practical factors which make engaging in digital feminist activism risky, exhausting, draining, and overwhelming, depending on the context. So, while we are confident that conversations around digital feminist activism against rape culture, sexism, and harassment will continue, we encourage researchers to continue to explore the experiences of those who are participating in such initiatives, so we can understand the fuller picture and long-term effects and impacts of such feminist activisms.

\section{References}

Ahmed, S (2010) Happy Objects. Pp. 29-51 in The Affect Theory Reader, ed. Melissa Gregg and Gregory, J. Seigworth. Durham, NC: Duke University Press.

Baer, H (2016) Redoing feminism: digital activism, body politics, and neoliberalism. Feminist Media Studies 16(1): 17-34.

Banet-Weiser, S and Miltner, KM (2016) (2016) \#MasculinitySoFragile: culture, structure, and networked misogyny, Feminist Media Studies 16(1): 171-174, DOI: $10.1080 / 14680777.2016 .1120490$

Berridge, S, and Portwood-Stacer, L (2015) Introduction: Feminism, Hashtags and Violence Against Women and Girls, Feminist Media Studies, 15(2): 341-344.

Citron, D (2014) Hate Crimes in Cyberspace. Cambridge: Harvard University Press.

CBS (2017) More than 12M "MeToo" Facebook posts, comments, reactions in 24 hours. Available at: https://www.cbsnews.com/news/metoo-more-than-12million-facebook-posts-comments-reactions-24-hours/ (accessed 1 December 2017) 
Dean, J (2005) Communicative Capitalism: Circulation and the foreclosure of politics. Cultural Politics, 1(1): 51-74 .

Dixon, K, (2014) Feminist online identity: Analyzing the presence of hashtag feminism. Journal of Arts and Humanities, 3(7), p.34.

Duffy, EB (2015) Gendering The Labor Of Social Media Production. Feminist Media Studies 15(4): 710-714.

Gill, R (2016) Post-postfeminism?: new feminist visibilities in postfeminist times, Feminist Media Studies, 16(4): 610-630, DOI:

10.1080/14680777.2016.1193293

Ging, D (2017) Alphas, Betas, and Incels: Theorizing the Masculinities of the Manosphere Men and Masculinities 1-20 http://journals.sagepub.com/doi/full/10.1177/1097184X17706401

Horeck, T (2014) \# AskThicke:"Blurred Lines," Rape Culture, and the Feminist Hashtag Takeover. Feminist Media Studies 14(6): 1105-1107.

Jane, EJ (2014) "Your a ugly, whorish slut": Understanding e-bile. Feminist Media Studies 14(4): 531-46.

Jane, EJ (2017) Misogyny Online: A short (and brutish) history. London, Thousand Oaks \& New Delhi: Sage

Keller, J, Mendes, K and Ringrose, J (2016) Speaking "unspeakable things:" Documenting digital feminist responses to rape culture, Journal of Gender Studies, 27(1): 22-36. https://doi.org/10.1080/09589236.2016.1211511

Keller, J and Ringrose, J (2015) "But then feminism goes out the window!": exploring teenage girls' critical response to celebrity feminism, Celebrity Studies 6(1): 132-135

Kim, C and Ringrose, J (2018 in press) "Stumbling Upon Feminism": Teenage Girls' Forays into Digital and School-Based Feminisms. Girlhood Studies, 11(2):

McRobbie, A (2016) Be Creative: Making a Living in the New Cultural Industries. Cambridge \& Malden, MA: Polity Press.

Mendes, K, Ringrose, J and Keller, J (forthcoming) Digital Feminist Activism: Girls and Women Fight Back Against Rape Culture. Oxford: Oxford University Press.

Munro, E (2013) Feminism: A fourth wave?. Political insight 4(2): 22-25.

Olson, CC (2016) \#BringBackOurGirls: digital communities supporting real-world change and influencing mainstream media agendas. Feminist Media Studies 16(5): $772-87$.

O’Toole, E (2015) Personal Interview, 11 May.

Phipps, A, Ringrose, J, Renold, E and Jackson, C (2017) Rape culture, lad culture and everyday sexism: researching, conceptualizing and politicizing new mediations of gender and sexual violence. Journal of Gender Studies, 1-15. 
Poland, B (2016) Cybersexism in the $21^{\text {st }}$ Century. Lincoln: University of Nebraska Press.

Powell, A, and Henry, N (2017) Sexual Violence in a Digital Age. Basingstoke:

Palgrave Macmillan.

Rentschler, C (2015) \#Safetytipsforladies: Feminist Twitter Takedowns of Victim Blaming. Feminist Media Studies 15(2): 353-356.

Retallack, H, Ringrose, J and Lawrence, E (2016) “Fuck your body image:' Teen girls' Twitter and Instagram feminism in and around school. In Coffey J, Budgeon S, and Cahill H (Eds.) Learning Bodies: The Body in Youth and Childhood Studies. London: Springer. Pp. 85-103

Ringrose, J and Renold, E (2016a) Cows, Cabins and Tweets: Posthuman Intraacting Affect and Feminist Fires in Secondary School in C. Taylor and C. Hughes (eds.) Posthuman Research Practices in Education, London: Palgrave.

Ringrose, J and Renold, E (2016b) Teen Feminist Killjoys? Mapping Girls' Affective Encounters with Femininity, Sexuality, and Feminism at School. In Mitchell C and Rentschler C (Eds.) Girlhood and the Politics of Place, New York: Berghahn. Pp. 104-121

Salter, M (2016) Crime, Justice and Social Media, London: Routledge.

Shaw, A (2014) The internet is full of jerks because the world if full of jerks: What feminist theory teaches us about the internet. Communication and Critical/Cultural Studies 11(3): 273-7.

Thrift, S (2014) '\#YesAllWomen as a feminist meme event. Feminist Media Studies 14(6): 1090-1092.

Teotonio, I (2014) Women find power in \#BennRapedNeverReported hashtag. Toronto Star, 5 November Available at: https://www.thestar.com/life/2014/11/05/women_find_power_in_beenrapedne verreported_hashtag.html (Accessed 17 December 2017).

Tsai, A (2015) Personal Interview, 18 May.

Vickery, J. and, Everbach, T, (2018) Mediating Misogyny: Gender, Technology, and Harassment, London: Palgrave

'This work was supported by the Arts and Humanities Research Council (UK) [grant number AH/L009587/1] "Documenting Digital Feminist Activism: Mapping Feminist Responses to New Media Misogyny and Rape Culture. 